\title{
Bioconversion of Commercial and Waste Glycerol into Value-Added Polyhydroxyalkanoates by Bacterial Strains
}

\author{
Joao Snoei de Castro, Luong Dang Nguyen and Jukka Seppala* \\ Laboratory of Polymer Technology, Department of Biotechnology and Chemical Technology, Aalto University, School of Chemical Technology, Finland
}

\begin{abstract}
The industrial conversion of renewable resources into bio-based materials has been increasingly receiving attention from an economic and, in particular, an environmental point of view. Among these bioresources, glycerol represents one of the most important base materials for the manufacturing of bulk and higher-valued products. This is mainly based on the increasing amounts of waste glycerol due to the rising production of biodiesel and other oleochemicals, as well as on the applicability of glycerol as a water-soluble carbon source for a wide range of microbial productions. Polyhydroxyalkanoates (PHAs) are biodegradable and environmentally friendly biopolymers, and the major contributor to PHA production is the substrate cost, therefore it is desirable to produce PHA from waste residues like biodiesel byproducts. Since soil ecosystems have a rich, but still insufficiently studied microbial flora, the ability of bacteria isolated from Finnish soils and sediments were investigated for the production of valueadded materials such as Polyhydroxyalkanoates based on pure and waste glycerol as carbon source. 1 out of 40 isolated strains was selected for further studies based on ability to produce PHA on mineral medium and identified as Halomonas sp SA8 with up to $56 \%$ of Polyhydroxyalkanoate accumulation. The produced biopolymer was recovered and identified as PHB homopolymer.
\end{abstract}

Keywords: Glycerol; Bioconversion; Biopolymers;

Polyhydroxyalkanoates

\section{Introduction}

In the last few years, biofuels have gained more and more importance because of the depletion of fossil fuel resources and the increasing prices for oil and petrochemical products. Another reason for the risen production of biofuels and bioenergy from renewable resources is the growing concern about global warming caused by carbon dioxide emissions from the use of fossil fuels. Biofuels are plant-based, and it has thus been thought that their use does not add extra $\mathrm{CO}_{2}$ greenhouse gas to the atmosphere [1,2]. On the other hand, there was and still is also an increasing concern about biofuels as the replacements for the traditional fossil fuels because it may lead to additional demands for some types of food and can thus enhance the price of that food causing direct increase of hunger spreading in the world, as well as their production is often accompanied by the formation of liquid or solid wastes. Industrial waste production and pollution are also topical issues as many countries and cities experience difficulties in managing their increasing waste volumes in an effective and environmentally sound way [3]. Not only does the visibility of solid waste classify it as environmentally unfriendly, but the lengthy time it takes to be fully degraded causes it to be labeled as a pollutant, and when waste is not managed properly it can cause health as well as environmental risks [4].

Therefore, the bioconversion of waste material from the production of biofuels into value-added chemicals would represent an optimum combination of waste (water) treatment and a sustainable production in the frame of modern white biotechnology.

Biodiesel can replace petroleum diesel, as it is produced from animal fats and vegetable oils, however about $10 \%$ of final product results in glycerol as the main byproduct (Figure 1) [5]. In some European countries, the production of glycerol has increased significantly due to biodiesel uptake. As a consequence prices have fallen, the majority of companies that chemically produced glycerol have shut down business, and the excess of glycerol generated may become an environmental problem, since it cannot be disposed of in the environment [6].
The utilization or disposal of this glycerol is complex, expensive and becomes an increasing impact factor in the economic situation of the related industry. An efficient use of the glycerol produced from this processing does not yet exist. Considering the increasing need for renewable fuels throughout the world and the increasing demand and production of biodiesel, an excess of glycerol will be available in the world [7].

Glycerol is a small uncharged molecule which, at least at high concentrations, can cross the cytoplasmic membrane through passive or facilitated diffusion and can be used as a carbon source by many microorganisms. One of the most promising applications for the use of glycerol is its bioconversion to value-added compounds through microbial fermentation. Besides high-value surfactants and enzymes, biopolymers can also be produced by microorganisms from glycerol [8].

Polyhydroxyalkanoates (PHAs) represent a complex class of naturally occurring bacterial polyesters that are synthesized intracellularly under unbalanced growth conditions as a mechanism to store excess carbon and energy, the PHA molecule is comprised of repeating units (monomers) of $\beta$-hydroxyalkanoic acids joined by ester bond between the carboxyl group of one monomer and the hydroxyl group of the neighboring monomer [9]. Generally, PHA is grouped into two main classes based on the carbon chain length of the monomers (short chain length and medium chain length). PHAs are

*Corresponding author: Jukka Seppala, Laboratory of Polymer Technology Department of Biotechnology and Chemical Technology, Aalto University, School of Chemical Technology, P.O. Box 16100, 00076 Aalto, Finland, Tel: +358-400701142; Fax: +358-94512622; E-mail: jukka.seppala@aalto.fi

Received July 25, 2014; Accepted August 11, 2014; Published August 18, 2014

Citation: de Castro JS, Nguyen LD, Seppala J (2014) Bioconversion of Commercial and Waste Glycerol into Value-Added Polyhydroxyalkanoates by Bacterial Strains. J Microb Biochem Technol 6: 337-345. doi:10.4172/1948-5948.1000165

Copyright: (c) 2014 de Castro JS, et al. This is an open-access article distributed under the terms of the Creative Commons Attribution License, which permits unrestricted use, distribution, and reproduction in any medium, provided the original author and source are credited 


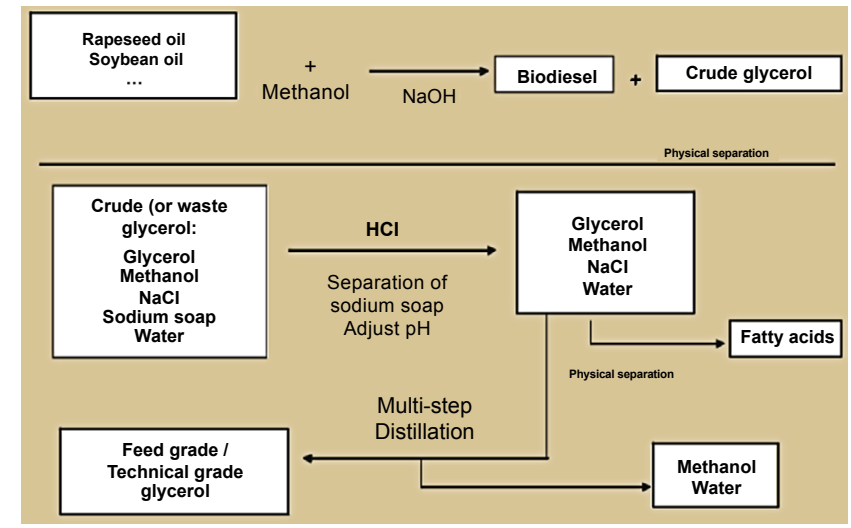

Figure 1: Purification steps for crude glycerol from biodiesel production (Source: SRS Engineering Corporation http://c1-preview. prosites.com/37030/ wy/docs/Glycerin\%20Purification.pdf)

biodegradable and biocompatible with human cells [10], and they may replace petroleum-derived polymers [11]

For the past decades, the production of PHA by bacteria has been extensively studied. However, there is scarce information about the diversity of PHA-producing bacteria isolated from Finnish Temperate soils. Some studies on bacteria isolated from Nordic Countries had shown that the accumulation of reserve polymers such as PHA could help bacteria to withstand starvation and hostile environmental conditions $[12,13]$. Therefore the accumulation of PHA in bacteria inhabiting Finnish soils might also increase the survival capabilities of these bacteria due to its northern location facing long winter season and poor nutrient availability.

A proper consideration of the bacterial capability from soil is needed to better understand and characterize the metabolic performances of microbial-waste-metabolism taking account of organisms isolated from inhospitable environment and their ability to convert industrial waste "non-conventional" carbon source into production of valueadded materials.

\section{Materials and Methods}

\section{Sampling site}

The samples were collected from several sites around the Aalto University Campus $\left(60^{\circ} 11^{\prime} 10^{\prime} \mathrm{N} 24^{\circ} 49^{\prime} 43^{\prime} \mathrm{E}\right)$. The Campus is located in the Eastern part of Espoo city in Finland. Surface soil (top 5-10 cm depth) and sediments were collected during spring time at 2012 with temperature ranging between $10-18^{\circ} \mathrm{C}$ in sterile sampling tubes and stored at $-20^{\circ} \mathrm{C}$ until use.

\section{Cultivation media}

For the selection and maintenance of the bacterial isolates, nutrient agar medium was used, composed of $(\mathrm{g} / \mathrm{L})$ : Peptone from potato 5 , Meat extract 3 and bacteriological agar 15 adjusted to $\mathrm{pH}$ 7.0. The conventional medium used for PHA production was the minimal mineral medium according to Kung [14], which contained $(\mathrm{g} / \mathrm{L})$ : $\mathrm{Na}_{2} \mathrm{HPO}_{4} \bullet_{2} \mathrm{H} 2 \mathrm{O} 4.5, \mathrm{KH}_{2} \mathrm{PO}_{4} 1.5, \mathrm{MgSO}_{4} \cdot 7 \mathrm{H}_{2} \mathrm{O} 0.2, \mathrm{NaCl} 1,\left(\mathrm{NH}_{4}\right)_{2} \mathrm{SO}_{4}$ $2, \mathrm{CaCl}_{2} \cdot 2 \mathrm{H}_{2} \mathrm{O} 0.02, \mathrm{NH}_{4} \mathrm{Fe}(\mathrm{III})$ citrate 0.05 , agar 15 , trace elements solution $1 \mathrm{~mL}$, adjusted to $\mathrm{pH}$ 7.0. Trace elements were composed of $(\mathrm{mg} / \mathrm{L}): \mathrm{ZnSO}_{4} \cdot 7 \mathrm{H}_{2} \mathrm{O} \quad 100, \mathrm{H}_{3} \mathrm{BO}_{3} 300, \mathrm{CoCl}_{2} \cdot 6 \mathrm{H}_{2} \mathrm{O} 200, \mathrm{CuSO}_{4}$ 6, $\mathrm{NiCl}_{2} \cdot 6 \mathrm{H}_{2} \mathrm{O} 20, \mathrm{Na}_{2} \mathrm{MoO}_{4} \cdot 2 \mathrm{H}_{2} \mathrm{O} 30$ and $\mathrm{MnCl}_{2} \cdot 2 \mathrm{H}_{2} \mathrm{O}$ 25. The components were sterilized separately due to precipitation (for $20 \mathrm{~min}$ at $120^{\circ} \mathrm{C}$ ). A modified mineral medium was used in the fermentation in the bioreactor containing $(\mathrm{g} / \mathrm{L}): \mathrm{Na}_{2} \mathrm{HPO}_{4} \cdot 2 \mathrm{H}_{2} \mathrm{O} 9, \mathrm{KH}_{2} \mathrm{PO}_{4} 3$, $\mathrm{MgSO}_{4} \cdot 7 \mathrm{H}_{2} \mathrm{O} 0.4, \mathrm{NaCl}, 1,\left(\mathrm{NH}_{4}\right)_{2} \mathrm{SO}_{4} 2, \mathrm{CaCl}_{2} .2 \mathrm{H}_{2} \mathrm{O}_{2}^{2} 0.02, \mathrm{NH}_{4}^{2} \mathrm{Fe}(\mathrm{III})$ Citrate 0.05 and trace element solution $2 \mathrm{ml}$ (all the chemicals used in this work were purchased by Sigma-Aldrich).

\section{Isolation of bacteria from collected samples}

Serial dilutions of the soil and sediments suspension in sterile distilled water $\left(10^{-4}-10^{-8}\right)$ were prepared and plated on nutrient agar plates. The agar plates were then incubated at $30^{\circ} \mathrm{C}$ until bacterial colonies were observed. All single colonies studied were selected randomly picked from the plates and purified by repeated dilutionstreaking on fresh nutrient agar plates. The bacterial genomic DNA was extracted and the product was amplified by PCR reaction according to the following procedure: The $30 \mu \mathrm{l}$ reaction mixture contained $6 \mu \mathrm{l}$ $5 \mathrm{xTaq} \& \mathrm{Go}$ (MP Biomedicals, Carlsbad, USA), $1.5 \mu$ of primer pair mix EubI-forward (5'-GAG TTT GAT CCT GGC TCA G-3') and 907r-reverse (5'-CCG TCA TTT C(AC)T TT(AG) AGT TT-3') both in a concentration of $10 \mathrm{pmol} / \mu \mathrm{l}$ and 20-30 ng template. The PCR products were purified with GeneClean Turbo Kit (MP Biomedicals) as recommended by the manufacturer. The fragments were sequenced in the Center of Molecular Biology (Center for Medical Research in Graz).

\section{Screening for PHA-producing Bacteria}

All the bacterial isolates were subjected to an initial Sudan Black B staining [15] to detect the presence of lipid granules in the bacteria. A positively-stained isolate was considered a potential PHA producer. A second specific staining was performed with Nile Red [16]; the isolates were first induced to accumulate PHA by culturing in mineral medium (described above) in nitrogen-limiting conditions containing $2 \%(\mathrm{v} / \mathrm{v})$ pure glycerol. The PHA accumulating colonies, after Nile red staining, showed bright red fluorescence on irradiation with UV light and their fluorescence intensity increased with increase in PHA content of the bacterial cells.

\section{Carbon sources}

Experiments were carried out using either commercial refined glycerol (Sigma, purity 99\%) or crude waste glycerol (adjusted to $\mathrm{pH}$ 7.0), a mixture of glycerol and fatty acids, gently donated by Professor Marques (UFPE-Brazil) and obtained in her laboratory as byproduct of Castor oil seed (Ricinus communis L.) were used in the experiments. Alternative carbon sources have also been tested Linoleic acid, Oleic acid and rape seed oil.

Glycerol concentration was measured using the Free Glycerol Reagent kit (Cat. F6428, Sigma, St. Louis, MO). The reactions were incubated for $5 \mathrm{~min}$ at $37^{\circ} \mathrm{C}$ and the absorbances were recorded spectrophotometrically at $540 \mathrm{~nm}$ (CARY 300 Spectrophotometer, Varian, Walnut Creek, CA) as described per the instructions of the manufacturer.

\section{Cultivation in platform shaker culture}

Preliminaries studies on PHA production were conducted in sterilized $500 \mathrm{~mL}$ Erlenmeyer flasks with $100 \mathrm{~mL}$ of mineral culture medium and inoculated with $5 \mathrm{~mL}$ of bacteria from a seed culture and incubated at $30^{\circ} \mathrm{C}$ with shaking at $180 \mathrm{rpm}$. The glycerol was added as sole carbon source in each test flask at 2 and $3 \%$ (for pure and waste glycerol). After a preliminary screening at $48 \mathrm{~h}$ to analyze dry biomass and PHA accumulation, a proper timing of fermentation was 
Citation: de Castro JS, Nguyen LD, Seppala J (2014) Bioconversion of Commercial and Waste Glycerol into Value-Added Polyhydroxyalkanoates by Bacterial Strains. J Microb Biochem Technol 6: 337-345. doi:10.4172/1948-5948.1000165

established at 24, 48, 72 and $96 \mathrm{~h}$; the process was monitored by Nile Red fluorescent dye to check the PHA production. The cells were harvested by centrifugation at $5000 \mathrm{rpm}$, for $20 \mathrm{~min}$, at $4^{\circ} \mathrm{C}$ (Beckman Coulter, avanti $\mathrm{J}-\mathrm{HC}$ ), washed with saline solution at $0.9 \%$ and lyophilized overnight. (Virtis, benchtop $2 \mathrm{~K}$ ). All the assays were done in triplicate.

\section{Batch bioreactor cultivation}

Bioreactor BBraun with a working volume of $2000 \mathrm{~mL}$ were filled with $950 \mathrm{~mL}$ of mineral medium adding glycerol (3\% v/v) as carbon source. The bioreactor was sterilized by autoclaving at $121^{\circ} \mathrm{C}$ for $20 \mathrm{~min}$. A pre-inoculum was cultivated in $50 \mathrm{~mL}$ mineral medium overnight at $30^{\circ} \mathrm{C}$. The bioreactor temperature was maintained at $30^{\circ} \mathrm{C}$ and $\mathrm{pH} 7$, aerated at 300 rev.min ${ }^{-1}$ with $2 \mathrm{vvm} \mathrm{O}_{2}$ injected into the system [14]. Every 12 hours during the experiment $10 \mathrm{~mL}$ of culture was centrifuged at $4.500 \mathrm{rpm}$, dry mass and PHA content were determined. All the assays were done in duplicate.

\section{Dry Biomass Weight Measurement}

Cell Dry Weights (CDW) were obtained by harvesting $5 \mathrm{~mL}$ samples and centrifuging at $4500 \mathrm{rpm}$ for $30 \mathrm{~min}$. Cell pellets were washed with $30 \mathrm{~mL}$ deionized water, re-centrifuged, and dried to a constant weight in a $60^{\circ} \mathrm{C}$ oven.

\section{PHA Extraction}

The PHA containing bacteria were collected by centrifugation at $4.500 \mathrm{rpm}$ for $30 \mathrm{~min}$, two times washed with water, frozen with liquid nitrogen and lyophilized for $24 \mathrm{~h}$. The dry biomass was washed once with methanol; the PHA was extracted by soxhlet with chloroform for $24 \mathrm{~h}$ at $60^{\circ} \mathrm{C}$ and filtered across a paper membrane filter (Whatmann). The chloroform was evaporated using a rotating evaporator and the resulting polymer kept for further analysis [17].

\section{Characterization}

FT-IR spectroscopy and NMR Analysis: The PHA extracted from the microorganism was analyzed by FT-IR spectroscopy (JASCO FT/ IR). It was used under the following conditions: spectral range, 4000$400 \mathrm{~cm}^{-1}$ to confirm the functional groups of the extracted polymer. Nuclear magnetic resonance spectra of samples were recorded at 300.1 $\mathrm{MHz}$ with a spectrum of $32 \mathrm{kB}$ data points using $\mathrm{CDCl}_{3}$ as solvent. For each analysis, $40 \mathrm{mg}$ of sample and $4 \mathrm{~mL}$ of solvent were employed. The equipment used was a NMR spectrometer model Mercury $300 \mathrm{MHz}$ (Varian Inc., Palo Alto, CA, USA).

Thermogravimetric Analysis (TGA): TGA measurement was performed on a Perkin-Elmer TGA 4000 instrument. Samples of approximately $10 \mathrm{mg}$ were used for each measurement. The samples were heated at a rate of $10^{\circ} \mathrm{C} / \mathrm{min}$ from room temperature to $600^{\circ} \mathrm{C}$ in a nitrogen atmosphere.

Scanning Electron Microscopy: Scanning electron microscope images were obtained by a field emission scanning electron microscope (FE-SEM, JEOL JSM-7500FA). Samples were sputtered with a thin layer of gold/palladium (Emitech K100X).

Mechanical Properties: The tensile strength measurements were performed with an Instron analyzer 4204 (TA Instruments) equipped with a film tension clamp at $23^{\circ} \mathrm{C}$. The specimens' dimensions were 20 $\mathrm{mm} \times 5.3 \mathrm{~mm} \times 0.03 \mathrm{~mm}$ (length $\times$ width $\times$ thickness). A preload force of $0.01 \mathrm{~N}$ was used and the force ramp $8 \mathrm{Nm}^{-1}$ until the rupture of sample. The device was previously calibrated, and a total of 5 measurements for each sample were made in order to ensure the reproducibility of the results.

\section{Results}

\section{Bacterial Isolation}

Nutrient medium was used to isolate the bacteria from the soil and sediment taken from surrounding of Aalto University Campus. Several distinguishable colonies from seven distinct sampling points were obtained after spreading the diluted samples on nutrient agar plates. The pure cultures were separated by transferring each colony to a new solid nutrient medium, a detailed macro and microscopic observation was done in order to differentiate the microorganisms. 40 bacterial strains were chosen according to morphological characteristics and considered for further studies, as the sum of clearly distinct microorganisms.

\section{Selection of PHA-accumulating bacteria}

The 40 purified bacterial strains were subjected to a preliminary selection by Sudan Black B staining onto mineral medium with glucose $(10 \mathrm{~g} / \mathrm{L})$. The results showed that 15 strains were positive and in 25 bacterial the PHA granules could not be detected. The isolates which were positively stained were further screened for PHA production using Nile red staining method grown in mineral medium using pure glycerol $(2 \% \mathrm{v} / \mathrm{v})$ as sole carbon source and limiting nitrogen. Out of 15 isolates which were able to grow and utilize glycerol only 5 isolates in the presence of Nile Red $(5 \mu \mathrm{g} / \mathrm{ml})$ showed fluorescence under UV light after $48 \mathrm{~h}$ of incubation at $30^{\circ} \mathrm{C}$ and $180 \mathrm{rpm}$. Based on the intensity of the fluorescence observed in the staining method and granule accumulation (Figure 2), as well as optical density (OD 420) measurement, one potential candidate (strain SA8) was selected for further studies on polymer production. The strain SA8 was taxonomically identified according to partial $16 \mathrm{~S}$ rDNA as belonging to the specie Halomonas sp.

\section{Evaluation of PHA production using alternative carbon sources}

To investigate the effect of carbon sources on the production of PHA, various carbon sources were provided at $1 \%(\mathrm{v} / \mathrm{v})$ in standard PHA mineral medium. Figure $3 \mathrm{a}$ shows the time course of biomass production $(\mathrm{CDW})$ by the isolate with different carbon sources. The microorganism utilized glucose, linoleic acid and oleic acid for growth, and biomass accumulation giving highest yield with glucose as substrate after $96 \mathrm{~h}$ of incubation reaching up to $4.05 \mathrm{~g} / \mathrm{L} \mathrm{CDW}$, followed by the

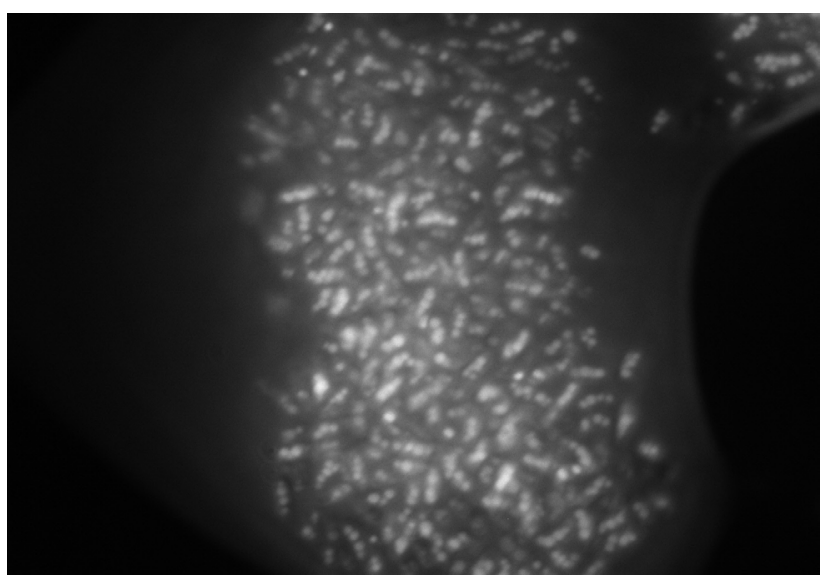

Figure 2: Fluorescence observation of $\mathrm{PHA}$ granules stained with Nile red afte grown in mineral medium with $2 \%$ glycerol during $48 \mathrm{~h}$ from strain SA 8 . 


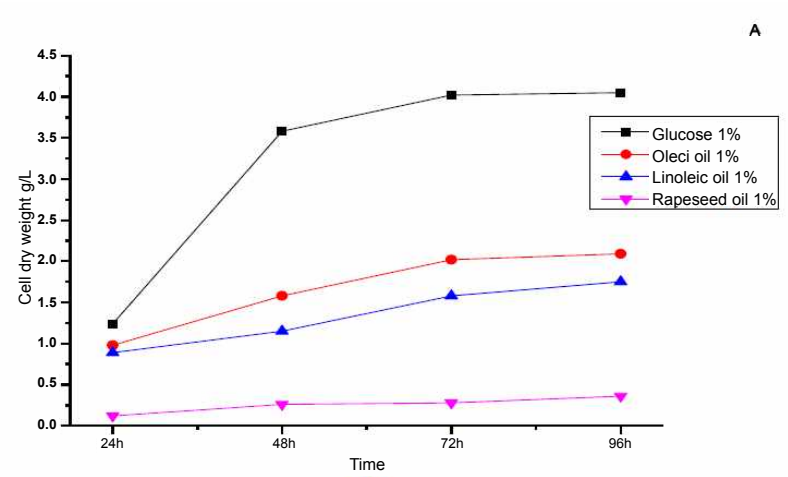

B

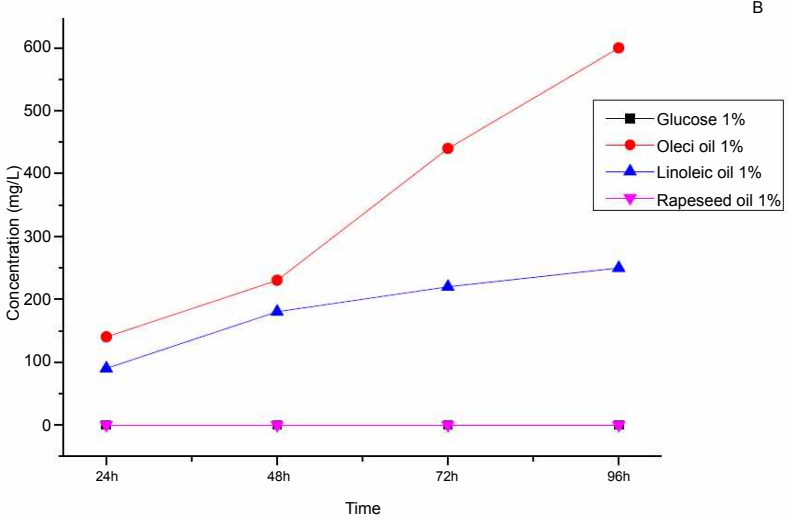

Figure 3: (A) Biomass production (CDW g/L) by Halomonas sp SA8 with different carbon sources. (B) PHA accumulation (mg/L) based on different substrates analyzed each $24 \mathrm{~h}$.

fatty acid groups oleic acid with $2.09 \mathrm{~g} / \mathrm{L}$ and linoleic acid $1.75 \mathrm{~g} / \mathrm{L}$, both after $96 \mathrm{~h}$ of cultivation. In contrast with the other fatty acids tested, rape seed oil was not a good substrate for microbial growth, and only reached $0.36 \mathrm{~g} / \mathrm{L}$ CDW after $96 \mathrm{~h}$ of cultivation.

Although the strain Halomonas sp SA8 used more efficiently glucose offered as carbon source in comparison with the other fatty acids, the selected substrate did not serve for the production of PHA, since no PHA has been detected as shown on Figure $3 \mathrm{~b}$. Of the 4 substrates tested, the fatty acids (Oleic oil and Linoleic oil) proved to be the best substrates for PHA accumulation, without any accumulation been observed in the rape seed oil culture.

On $1 \%$ oleic oil, the maximum yield of PHA was obtained after 96 $\mathrm{h}$ of cultivation, with PHA accumulating up to $0.6 \mathrm{~g} / \mathrm{L}$. At presence of linoleic oil, lower PHA levels were attained: $0.25 \mathrm{~g} / \mathrm{L}$; representing 28.7 wt $\%$ and $14.2 \mathrm{wt} \%$ respectively of PHA intracellular.

\section{Use of glycerol as carbon source}

The capability of using glycerol as carbon source was studied in Halomonas sp SA8. The remaining residual product was quantified through commercial kit spectrophotometrically at $540 \mathrm{~nm}$. The strain was cultivated on different amounts of pure and waste glycerol (Figure 4). Consumption was significantly affected at glycerol concentrations above $5 \%(\mathrm{v} / \mathrm{v})$ which were inhibitory, decreasing the growth rate and increasing the lag time. The isolate was not able to use efficiently the glycerol added into culture medium at high concentration, been detected more than $42 \mathrm{~g} / \mathrm{L}$ of the compound added initially after $96 \mathrm{~h}$ of fermentation according to measurement. Commercial pure glycerol were also tested in culture medium at $2 \%$ and $3 \%(\mathrm{v} / \mathrm{v})$, the final result indicated a consumption of $20.09 \mathrm{~g} / \mathrm{L} \sim 67 \%$ at the $3 \%(\mathrm{v} / \mathrm{v})$, as well as $15.44 \mathrm{~g} / \mathrm{L} \sim 77 \%$ at $2 \%(\mathrm{v} / \mathrm{v})$ of glycerol by the tested strain. The use of waste glycerol as suitable carbon source was also determined; at the same amount waste glycerol seems to be more difficult to be assimilated by the tested microorganism. Added in cultivation at $3 \%(\mathrm{v} / \mathrm{v})$ of waste $12.35 \mathrm{~g} / \mathrm{L} \sim 41 \%$ was metabolized; $8.7 \mathrm{~g} / \mathrm{L} \sim 43.5 \%$ of a $2 \%$ (v/v) culture was still remain in liquid after $96 \mathrm{~h}$.

The data showed that lower amount of glycerol has a better up take and use as carbon source, as well as it commercial form is more available to consume and biomass formation by Halomonas sp SA8.

\section{Production of PHA from glycerol}

The ability of strain SA8 to utilize cheap carbon sources for PHA accumulation was investigated in $500 \mathrm{~mL}$ Erlenmeyer flasks containing $100 \mathrm{ml}$ of mineral medium in the presence of $2 \%$ and $3 \%(\mathrm{v} / \mathrm{v})$ pure and waste glycerol. Cultures were incubated at $30^{\circ} \mathrm{C}$ and $180 \mathrm{rpm}$, and samples were taken at different intervals under sterile conditions for analysis. The Figure 3 showed that the strain was able to utilize both forms of glycerol as carbon sources for growth. Halomonas sp SA8 was cultivated in the conditions described above and found to grow and produce PHA at all concentrations. However, commercial form was the most suitable substrate to obtain high cell density as well as high PHA contents of the cells in comparison with the other one. The nitrogen source (ammonium sulphate) was completely depleted after approx. $48 \mathrm{~h}$ coinciding with the time when the polymer started to be obtained.

On 2\% (v/v) pure glycerol, the maximum yield of PHA was obtained after $96 \mathrm{~h}$ of cultivation, with biomass reaching $4.14 \mathrm{~g} / \mathrm{L} \mathrm{CDW}$ and PHA accumulating to $1.78 \mathrm{~g} / \mathrm{L} \sim 43 \mathrm{wt} \%$. At higher glycerol concentrations, higher biomass and PHA yields were observed $4.53 \mathrm{~g} / \mathrm{L} \mathrm{CDW}$ and 2.56 $\mathrm{g} / \mathrm{L}$ of PHA $\sim 56.5 \mathrm{wt} \%$ at $3 \%$ glycerol. In the case of waste glycerol, probably cell growth and PHA accumulation were inhibited due to substance present in the composition of material. Significant PHA and CDW yields are shown in this fermentation, being the best PHA production at $2 \%(\mathrm{v} / \mathrm{v})$ concentration with a biomass yield of $2.88 \mathrm{~g} / \mathrm{L}$ and PHA accumulation of $0.95 \mathrm{~g} / \mathrm{L} \sim 39 \mathrm{wt} \%$, and $33 \mathrm{wt} \%$ PHA at $3 \%$ waste glycerol (Figure $5 \mathrm{a}$ and $\mathrm{b}$ ).

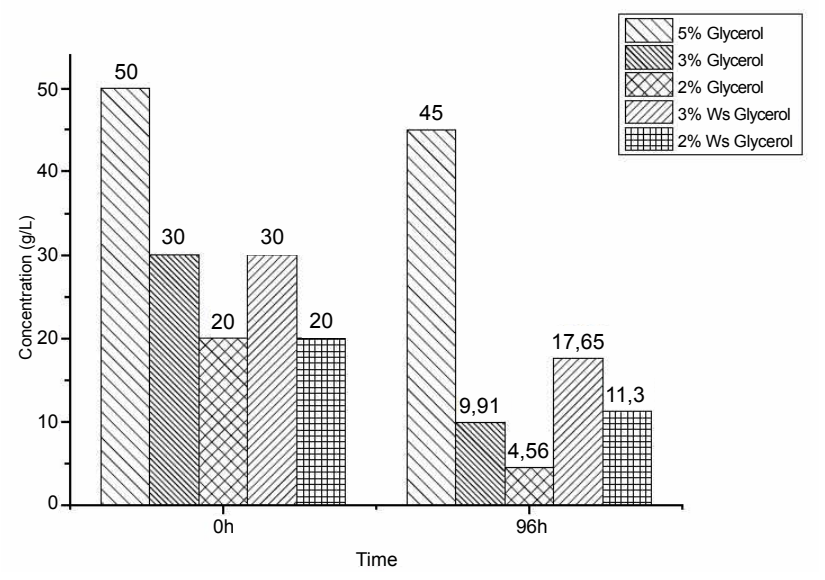

Figure 4: Evaluation of consumption of pure and waste glycerol (Ws) as carbon source at different concentrations by Halomonas sp SA8 grown on mineral medium. 

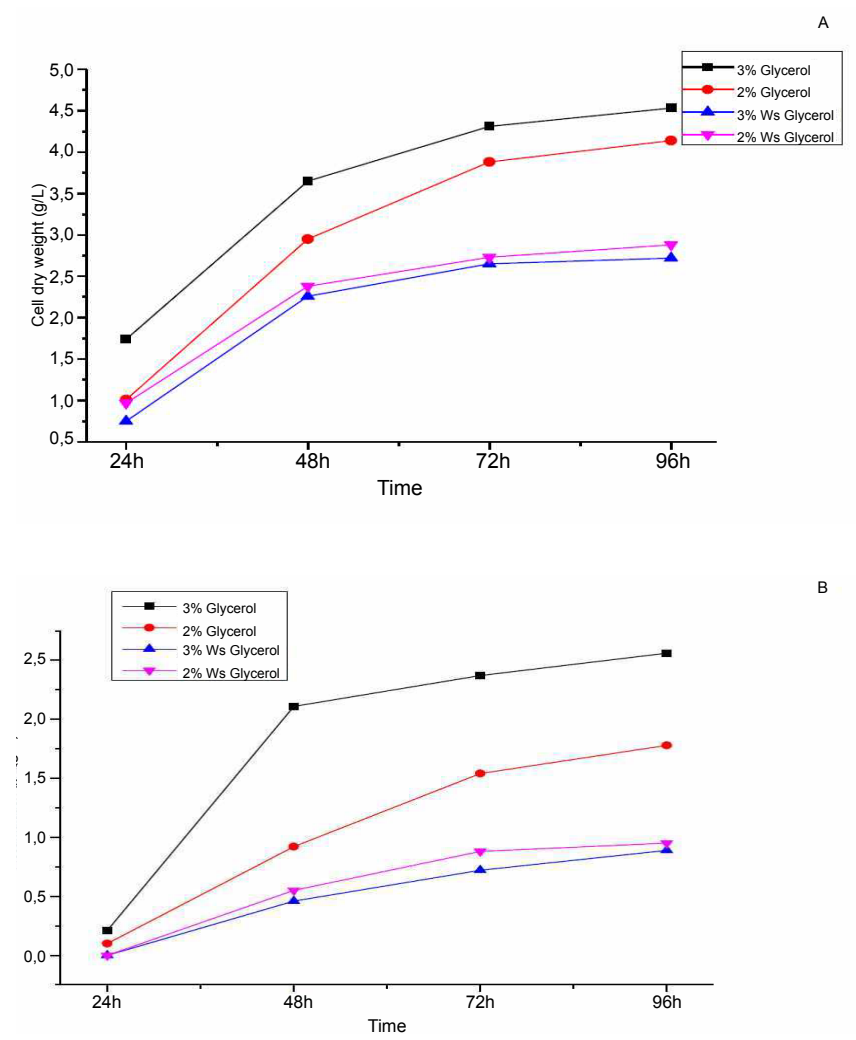

Figure 5: Time curves of fermentation with Halomonas sp SA8 using pure and waste glycerol at 2 and $3 \%(\mathrm{v} / \mathrm{v})$ concentrations: (A) dry biomass (CDW). (B) Polymer (PHA) accumulation.

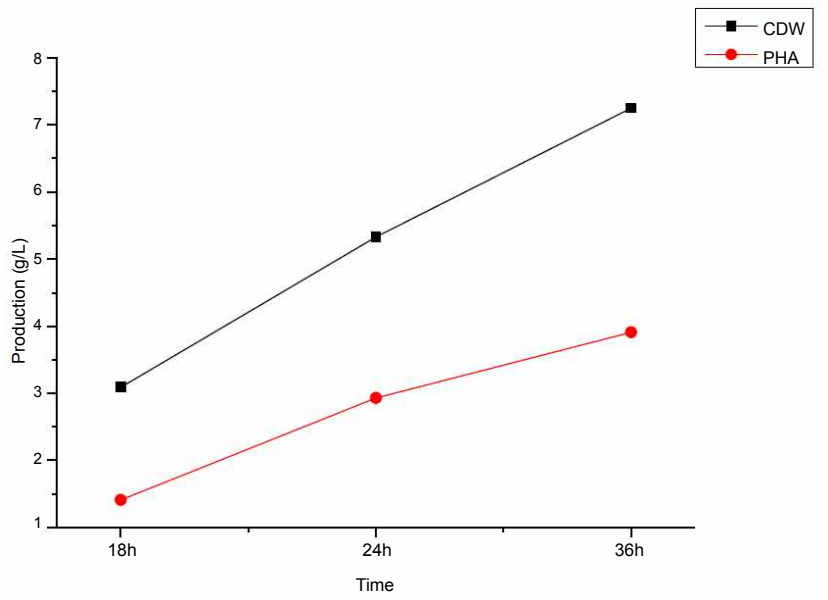

Figure 6: Time curves of fermentation with Halomonas sp SA8 using 3\% (v/v) glycerol as carbon source into stirring tank bioreactor.

\section{Production of PHA in Stirred Tank Fermentor}

Halomonas sp SA8 was cultivated for $36 \mathrm{~h}$ in a modified mineral medium (as described in the section 2.2), additional $1 \mathrm{~g} / \mathrm{L}$ of yeast extract had been supplemented into fermentation to improve nutrient content and glycerol uptake. Samples have been taken for biomass and polymer measurement regularly after beginning of the experiment. To increase the production of PHA, 3-L stirred bioreactor with 1-L working volume was considered using the optimal condition obtained from the Erlenmeyer flask scale (3\% v/v pure glycerol as sole carbon source). The CDW and PHA production as function of time are shown in Figure 6. The batch system reached a steady state with the CDW $(7.25 \mathrm{~g} / \mathrm{L})$ and the maximum PHA $(3.91 \mathrm{~g} / \mathrm{L})$ after $36 \mathrm{~h}$, representing $54 \mathrm{wt} \%$ of accumulation.

The strain started to accumulate biopolymer after $18 \mathrm{~h}$ of fermentation, and increased until the end of the experiment. After the first sampling time $(18 \mathrm{~h})$ the polymer content reached $1.41 \mathrm{~g} / \mathrm{L}$ with CDW $3.09 \mathrm{~g} / \mathrm{L}$ ( $45.6 \mathrm{wt} \%$ ) of CDM from glycerol as a carbon source. The second sampling lasted $24 \mathrm{~h}$ and the values were quantified as $5.33 \mathrm{~g} / \mathrm{L}$ with $2.93 \mathrm{~g} / \mathrm{L}$, respectively CDW and PHA formation. A total limitation of the nitrogen source was achieved after $18 \mathrm{~h}$ of fermentation, extra ammonium sulphate $(0.025 \mathrm{~g} / \mathrm{L})$ was added into system after $24 \mathrm{~h}$ to enhance cell metabolism. Regarding the carbon source evolution, the consumption was analyzed in the end of fermentation. The initial concentration of glycerol was $30 \mathrm{~g} / \mathrm{L}$, and it was completely consumed by the cells after $36 \mathrm{~h}$ of cultivation.

\section{Characterization of PHA}

NMR and FTIR spectroscopy analyses of the biopolymer produced in mineral medium supplemented with glycerol showed a qualitative evaluation of structural composition.

FT-IR results showed typical signals of PHA. FT-IR spectroscopy of PHA extracted from Halomonas sp SA8 showed intense absorptions typical to PHA at $1724-1740 \mathrm{~cm}^{-1}$ and at $1280 \mathrm{~cm}^{-1}$ corresponding to $\mathrm{C}=\mathrm{O}$ and $\mathrm{C}-\mathrm{O}$ stretching groups in ester, respectively.

After chloroform extraction, PHA was separated from biomass with hot ethanol (95\%) and analyzed by Nuclear Magnetic Resonance (NMR). The results showed a spectrum with the presence of three groups of signals characteristic of the Polyhydroxybutyrate (PHB) homopolymer: at $1.29 \mathrm{ppm}$ attributed to the methyl group, at $2.57 \mathrm{ppm}$ for the ethylene group adjacent to an asymmetric carbon atom and at $5.27 \mathrm{ppm}$ characteristic of the methylene group (Figure 7).

The morphology of PHA films has been observed through scanning electron microscopy. SEM revealed that the films made of glycerol had a very smooth and uniform surface morphology with small porosity been spread along the whole film (Figure 8).

The thermal degradation of PHA produced by Halomonas sp SA4 was investigated by TGA in the temperature range from $30^{\circ} \mathrm{C}$ to $600^{\circ} \mathrm{C}$. According to the (Figure 9) the temperature at $5 \%$ weight loss $(\mathrm{Td}(5 \%)$ ) observed for the studied $\mathrm{PHB}$ was reported at $220^{\circ} \mathrm{C}$.

Mechanical properties of the biopolymer film produced through flasks and bioreactor fermentation have been examined by tensile test, a standard technique to characterize mechanical properties of thin films, such as residual stresses and elastic modulus. According to the results showed in the measurements, apparently there was no significant difference in the mechanical properties between both films.

The average mechanical properties of the PHA films are reported in Table 1. Values of tensile modulus for single films of PHA have been evaluated through Instron analyzer in a room kept constantly with $50 \%$ of humidity and $23^{\circ} \mathrm{C}$ temperature with each experiment been repeated 5 times. The Young modulus measurements reached the value of 1.5 $\mathrm{GPa}$ in the tested sample. The breakdown within the fibers network during deformation and the rupture (tensile stress) occurs at $32 \mathrm{MPa}$ with $3.06 \%$ elongation. 
Citation: de Castro JS, Nguyen LD, Seppala J (2014) Bioconversion of Commercial and Waste Glycerol into Value-Added Polyhydroxyalkanoates by Bacterial Strains. J Microb Biochem Technol 6: 337-345. doi:10.4172/1948-5948.1000165

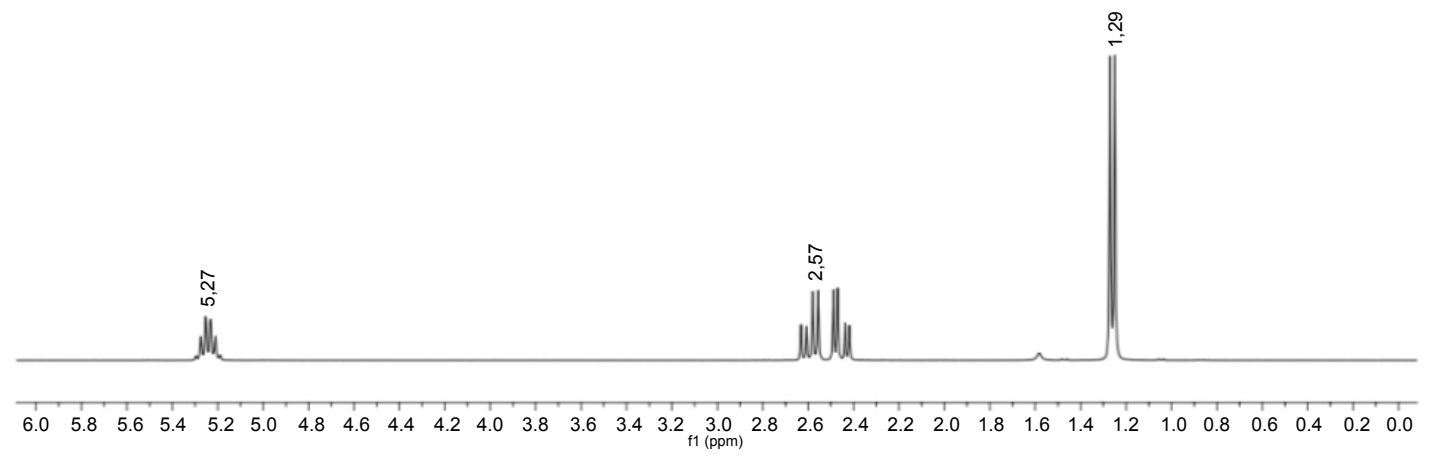

Figure 7: PHB chemical structure. H NMR spectra of PHB produced by Halomonas sp SA8 using glycerol as carbon source.

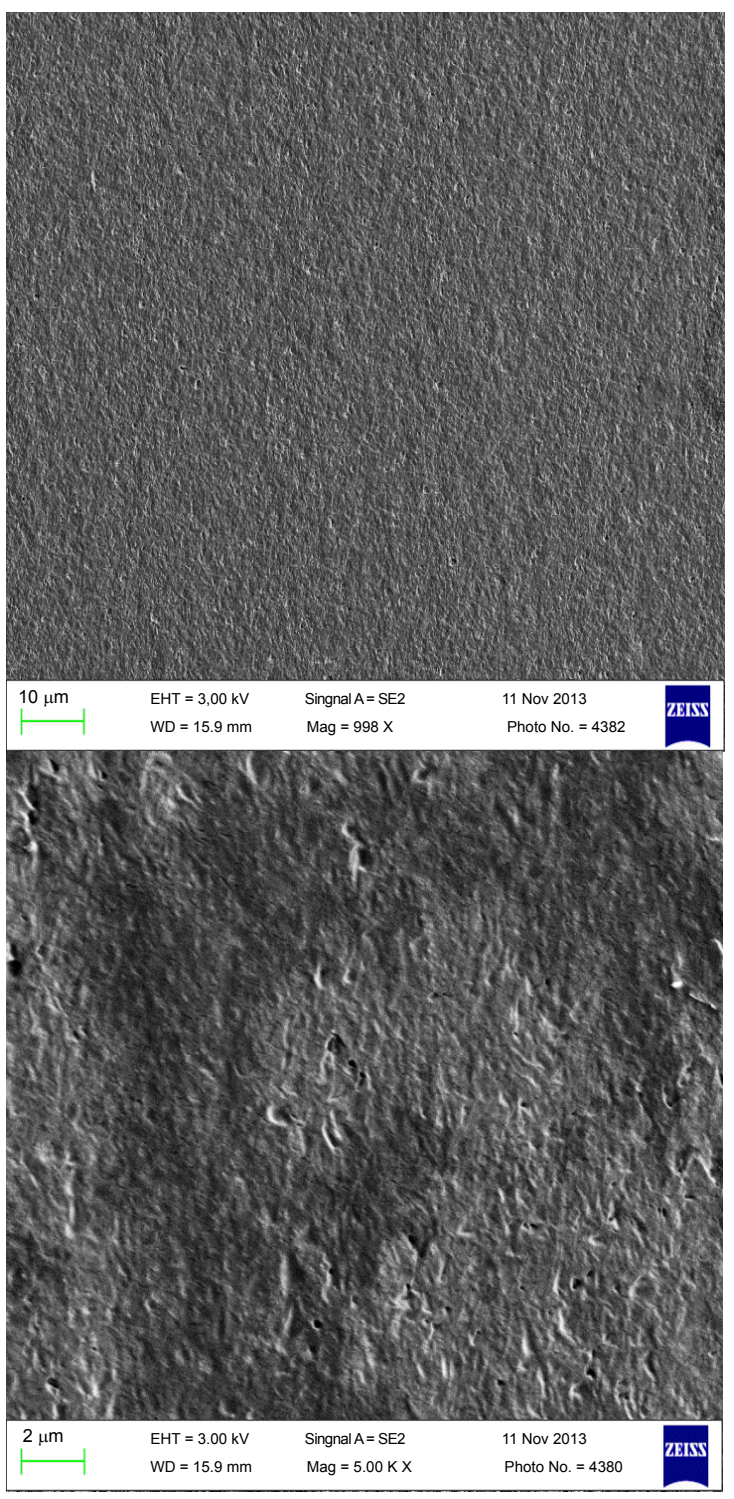

Figure 8: Scanning electron micrographs showing surface morphology of PHB films produced by Halomonas $s p$ SA8 from glycerol.

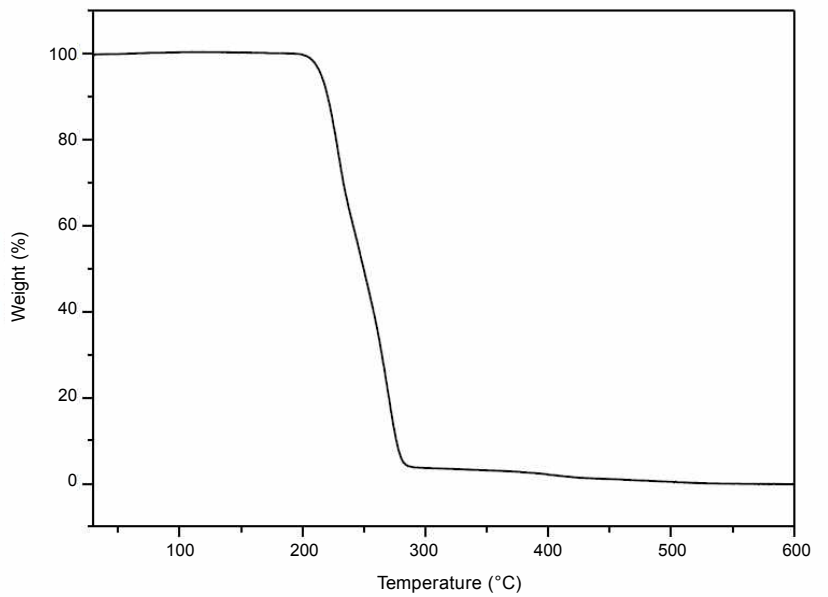

Figure 9: Thermogravimetric analysis of PHB from Halomonas $s p$ SA8 using glycerol as carbon source.

\begin{tabular}{|l|c|c|c|c|}
\hline Samples & State & $\begin{array}{c}\text { Young's Modulus } \\
\text { (GPa) }\end{array}$ & $\begin{array}{c}\text { Tensile Strength } \\
\text { (MPa) }\end{array}$ & Elongation (\%) \\
\hline PHA Film & Dry & 1.51 & 32 & 3.06 \\
\hline
\end{tabular}

Table 1: Mean mechanical property of polyhydroxyalkanoate films produced by Erlenmeyer flasks and Stirring Bioreactor with pure glycerol $(3 \% \mathrm{v} / \mathrm{v})$ from Halomonas sp SA8.

\section{Discussion}

Finnish soils are characterized by extreme conditions such as long periods of low temperatures, multiple episodes of freezing and thawing during spring and fall and relatively wide annual temperature variation. It is often assumed that the soil microbial activity is minimal outside the growing season [18]. Potential applications for cold-active microorganisms and microbial by-products have also been a strong motivation for the exploration of extremely cold environments and numerous novel bacterial species have been isolated and described from these environments [19].

In the presented study samples were collected from soil and sediments during spring time (05.2012), a total of 40 bacterial isolates from soils and sediments were screened for PHA accumulation. Out of these, 5 isolates were positive for Nile red staining in presence of 
glycerol, and 1 exhibiting a significantly high intensity of fluorescence was selected for further experiments. Based on DNA analysis, the strain was identified as members of the genus Halomonas, belonging to the specie Halomonas sp. The genus Halomonas is well known for being able to synthetize PHA, many species in this family assimilate several different carbon sources that can be obtained from waste residues or by-products and has the potential to be used as inexpensive raw materials for PHA production [20]. According to [21] Halomonas boliviensis has been already reported to produce polyhydroxyalkanoates from several different carbon sources, like glucose, xylose, sucrose, maltooligosacharides, sodium acetate and butyric acid. Currently alternatives ways for improving PHA production are being investigated by other researchers with representatives of genus Halomonas by using less expensive substrates and scaling-up fermentation. Studies on production of PHAs by halophilic strains are still recent. The advantage of using of halophilic microorganisms in PHA production systems is related to their ability to grow optimally at high salt concentrations. At determined concentrations of salt, the growth of nonhalophilic microorganisms is prevented, hence allowing a process without strict sterile conditions and reducing the inherent costs, such as the costs of the energy required for sterilizing the equipment for fermentation and culture media [22]. Recently, it was reported the production of PHB by moderately halotolerant Halomonas campisalis MCM B-1027, isolated from Lonar Lake, India. This organism accumulates PHA in the range of $45-61 \%$, reaching up to $7.2 \mathrm{~g} / \mathrm{L} \mathrm{CDW}$ and $4.1 \mathrm{~g} / \mathrm{L}$ PHA when grown in production medium containing maltose and yeast extract as carbon and nitrogen source respectively [23].

One of the main problems preventing the commercial expansion of microbial polymers is its high cost, even with all the news achievements the price of PHA is still considered much higher than that of synthetic plastic [24]. One considered strategy to reduce its price would be the use of more inexpensive carbon sources [25]. Since PHA production from pure glucose, fructose or sucrose has already been well studied and optimized, an option would be the development of new technology and the use of alternative cheaper carbon sources as a key factor in further reducing the PHA production cost. Fatty acids are good material for PHA production because they are inexpensive renewable carbon sources; in addition, the theoretical yield coefficient of PHA from fatty acid is considerably higher than that from glucose [26].

In the present study, fatty acids have been tested as substitute of glucose on PHA and biomass accumulation in batch cultivation. Oleic and Linoleic acid were metabolized by our tested strain responsible for $28.7 \mathrm{wt} \%$ and $14.2 \mathrm{wt} \%$ of biopolymer production, however biomass accumulation was still considered low almost the half in comparison with the experiment using pure glucose as energy source. Tsuge [27] reported that bacterial fermentation using plant oils or fatty acids has some problems, been one of the major problem the relatively low growth rate quantified on CDW per g of fatty acid. Further experiments are still needed to improve the biomass formation on fatty acids.

Biodiesel is a popular alternative fuel. It is basically carbon neutral, has emissions equivalent to or below diesel, is biodegradable, nontoxic, and is significantly cheaper to manufacture than its petroleum equivalent. However there is one significant drawback: for every 10 gallons of biodiesel produced, roughly 1 gallon of glycerin is created as a byproduct. Although glycerin does have its industrial uses, current biodiesel production has already exceeded market demand, leaving large amounts of practically worthless glycerin in the manufacturers' hands, leading to increased disposal costs [28]. Crude glycerol may contain from 40 to $80 \%$ glycerol, with a high degree of variability from one manufacturer to the next [6]. Technical grade glycerol is a refined, high purity product, with most contaminants nearly completely removed. It is free of methanol, MONG, soaps, salts, and other foreign matter. USP grade glycerol is suitable for personal care and specialty applications, been considered in reasonably concentration as a suitable carbon source for microbial processes.

High concentration of glycerol may cause interference on microbial growth due to decrease on availability of free water to cell metabolism, this may be the cause of lower consume observed by the tested strain in culture medium with $3 \%(\mathrm{v} / \mathrm{v})$ pure glycerol in comparison with $2 \%(\mathrm{v} / \mathrm{v})$ and the explanation for inhibition at $5 \%(\mathrm{v} / \mathrm{v})$. Even though biodiesel by-products are not considered an available source of nutrient for bacterial development due to excess of contaminants, the isolate Halomonas sp SA 8 was able to grow and consume up to $41 \%$ of waste glycerol even at high concentration such as $30 \mathrm{~g} / \mathrm{L}$.

Batch fermentation in Erlenmeyer flaks was carried out in this study in order to prove the ability of microorganism in converting biodiesel by-product into biopolymer for further characterization. The strain SA8 was able to accumulate $56.5 \mathrm{wt} \%$ of PHA in the presence of higher volume of pure substrate ( $3 \%$ glycerol), however similar behavior was not observed on crude glycerol-batch, which both concentration showed approximately the same value for biomass and PHA content, probably due to contaminants in the substrate. As a byproduct of biodiesel production waste glycerol possesses low value and difficult metabolism due to the presence of impurities such as methanol, water, inorganic salts free fatty acids and (other) MONG (Matter of Organic Non Glycerol) [29]. Both values can be considered promising, if compared to other bacteria described in recent works $[30,31]$. According to $[32,33]$, waste glycerol may be used as important feedstock for polyhydroxyalkanoates production in which the bacterial cultures were able to reach maximum PHB content of $47 \%(\mathrm{cdw})$; the same has been observed by $C$. necator with a PHB accumulation of $38 \%$ as sole carbon source. The use of crude glycerol by soil microorganisms showed in this paper may be considered as a good achievement for solving the problem of excess of intermediate waste products during biodiesel synthesis. The polymer started to be accumulated when the nitrogen source was limited. Nitrogen limitation is proved by literature as the initiator of PHA production because the formation of proteins ceases and the flux of carbon are redirected to polymer synthesis [34].

Even though PHAs are been considered as good candidates for replacing petroleum based plastic, the high production cost has limited their use in a wide range of applications. Several fermentation processes are employed in wild strains and recombinant species to develop and improve for more economical production of PHA [35]. The productivity of $\mathrm{PHB}$ cultivated in bioreactors has been reported to reach up to $3 \mathrm{~g}$ of $\mathrm{PHB} /$ liter/h by employing $A$. eutrophus and recombinant E. coli [36].

In our study, Halomonas sp SA8 was cultivated in a stirring tank bioreactor with glycerol as sole carbon source at $30^{\circ} \mathrm{C}$ and $\mathrm{pH}$ 7. The cultivation was carried out under limited nitrogen and excess carbon sources, though extra additional nitrogen was supplied during the fermentation. The glycerol concentration in the batch was fixed initially at $30 \mathrm{~g} / \mathrm{L}$, and completely metabolized after 36 hours of cultivation. The strain was able to accumulate PHA in Erlenmeyer flaks, therefore a stirring batch culture in bioreactor was carried out to induce an efficiently production of PHA by improving aeration and $\mathrm{pH}$. By optimizing fermentation [37] could increase the PHB content to $88 \%$ of cell dry weight and PHB productivity to $4.94 \mathrm{~g} / \mathrm{L} / \mathrm{h}$. Significant improvement on biomass and polymer production has been observed 
in the experiment, raising CDW yield to $7.25 \mathrm{~g} / \mathrm{L}$ and maximizing the PHA concentration $(3.91 \mathrm{~g} / \mathrm{L})$ after $36 \mathrm{~h}$. By using a fed-batch culture with P. putida strain using oleic acid as carbon source [36] were able to enhance cell concentration, PHA concentration and PHA content obtained in $34 \mathrm{~h}$, resulting in the PHA productivity of $1.79 \mathrm{~g} / \mathrm{L} / \mathrm{h}$.

Although Suzuki, et al. [38] observed that the maximum PHA accumulation has been achieved in cells that were not supplied with nitrogen; we attempted to improve the PHA content of cells and the yield of biomass in the fermentation by adding extra nitrogen source. Yeast extract was supplied in the beginning of the experiment to the stirred tank bioreactor. In all experiments after 18 hours of cultivation all the nitrogen has been consumed. 24 hours after inoculation of the bioreactor with Halomonas sp SA8, nitrogen was fed again into culture to improve the uptake of glycerol and biomass growth. The strategy is in accordance with [39] which described the difference in the quantity of PHA produced by Pseudomonas putida CA-3 supplied with nitrogen compared to those not supplied with nitrogen, the highest percentage of PHA accumulated by the tested strain ( $43 \mathrm{wt} \%$ of CDW) was registered with nitrogen feed into cultivation.

The functional groups of the extracted PHA granules were identified as $\mathrm{C}=\mathrm{O}$ group by FT-IR spectroscopy. The results elucidated in this work are in agreement with other references in the literature $[40,41] 1724 \mathrm{~cm}^{-1}, 1740 \mathrm{~cm}^{-1}$ (ester $\mathrm{C}=\mathrm{O}$ valence) and $1280 \mathrm{~cm}^{-1}$ (ester C-O). Similar peaks were also observed by [42] from the FTIR spectral result of sample $\mathrm{HG}, \mathrm{C}=\mathrm{O}$ stretching at $1720 \mathrm{~cm}^{-1}$. The main bands and peaks of the FTIR and ${ }^{1} \mathrm{H}$ NMR spectra correspond to PHB, according to those found in the literature [42]. Furthermore, the chemical signals obtained in the present work agree with those obtained by [43] for a PHB produced by fermentation. These results together with the FTIR analysis showed that strain SA8 was able to accumulate PHB using glycerol as a substrate.

For Thermogravimetric Analyses (TGA) of the PHB produced by the tested strain, the results were comparable to those quoted on literature for standard PHB [44]. It has been reported a rapid thermal degradation between 245 and $290^{\circ} \mathrm{C}$ while the standard $\mathrm{PHB}$ represented at between 255 and $293^{\circ} \mathrm{C}$. It has indicated that the biopolymeric material obtained by glycerol fermentation can possibly be further used in a large scale processing of bioplastic with good thermal stability when compared with standard polyhydroxyalkanoates.

Most studies of the mechanical properties of bacterial PHAs have been done with $\mathrm{PHB}$ and poly (3-hydroxybutyrate-co-3hydroxyvalerate) (HBco-HV) [45]. The mechanical properties of PHB can reach significant values; that includes Young's modulus (3.5 GPa) an d tensile strength (MPa) similar to those of polypropylene (40 MPa), but the elongation to break of PHB (6\%) is significantly lower than that of polypropylene [46]. In the above study, the Young's modulus, elongation at break, and tensile strength of PHA films were obtained from the analysis of at least 5 measurements for each experiment. The confidence limit at $95 \%$ was analyzed according to Student's $t$ test. Elongation at break of PHA was characterized ca. 3.06\% and apparently was not influenced by the cultivation process. Young's modulus and tensile strength at break were also not affected by the cultivation process either Erlenmeyer flaks or Fermenters have shown the same results. Mean value of Young's modulus of PHA was $1.5 \mathrm{GPa}$ and tensile strength at break reached $32 \mathrm{MPa}$. Similar results have also been mentioned by other authors [47].

Poly[(R)-3-hydroxy butyrate] samples were examined by [48] to access their mechanical properties, under non-isothermal conditions and inert atmosphere, although the elongation break showed by the authors has been $50 \%$ higher than the one achieved by strain SA8, both Young's modulus and tensile break presented very similar characteristics to PHA films produced by Halomonas sp.

\section{Conclusion}

Microorganisms from Nordic regions are often viewed as an unexploited resource for biotechnological application. In this study, inexpensive and alternative compounds (pure and waste glycerol) were used as a sole carbon source to produce value-added product such as biopolymers. The objective of this study was to assess the production of Polyhydroxyalkanoate (PHA) in bacteria isolated from soil and sediments collected from different locations in the city of Espoo (Finland). Different bacterial strains were isolated and screened from soil and sediments for PHA production, and based on their performance for PHA production from biodiesel byproduct; one bacterial isolate with desirable performance was selected. The wild-type strain of Halomonas sp SA8 was described in this work, as a microorganism able to grow efficiently in a mineral culture medium with low nitrogen content and excess of carbon sources, and can be regarded as potential bacteria for conversion of biodiesel byproduct containing glycerol into PHA. It has also been confirmed that glycerol is potentially viable product to be used as a carbon source for commercial, large-scale production of value-added products such as PHA. Another significant finding in this study is that our isolate could also accumulate PHA up to $29 \mathrm{wt} \%$ using oleic oil as carbon substrates. According to all the above findings, the strain SA8 could be utilized to achieve cost effective production of biodegradable polymers, which is a great hindrance in the commercial production of PHA.

\section{Acknowledgement}

We are grateful to Professor Heikki Ojamo from the Laboratory of Bioprocess Engineering at Aalto University for allowing us to use the Bioreactor and microbiology facilities. And we also would like to thank Professor Marques from the Laboratory of Process Fermentation at University of Pernambuco for the donation of waste glycerol used in this paper.

\section{References}

1. Willke T, Vorlop KD (2004) Industrial bioconversion of renewable resources as an alternative to conventional chemistry. Appl Microbiol Biotechnol 66: 131142.

2. Hatti-Kaul R, Törnvall U, Gustafsson L, Börjesson P (2007) Industrial biotechnology for the production of bio-based chemicals--a cradle-to-grave perspective. Trends Biotechnol 25: 119-124

3. Hill J, Nelson E, Tilman D, Polasky S, Tiffany D (2006) Environmental economic, and energetic costs and benefits of biodiesel and ethanol biofuels. Proc Natl Acad Sci U S A 103: 11206-11210.

4. AGUNWAMBA JC (1998) Solid Waste Management in Nigeria: Problems and Issues. Environ Manage 22: 849-856.

5. Mu Y, Teng H, Zhang DJ, Wang W, Xiu ZL (2006) Microbial production of 1,3-propanediol by Klebsiella pneumoniae using crude glycerol from biodiesel preparations. Biotechnol Lett 28: 1755-1759.

6. da Silva GP, Mack M, Contiero J (2009) Glycerol: a promising and abundant carbon source for industrial microbiology. Biotechnol Adv 27: 30-39.

7. Dasari MA, Kiatsimkul P, Sutterlin WR, Suppes GJ (2005) Low-pressure hydrogenolysis of glycerol to propylene glycol. Appl Catalysis 281: 225-231.

8. Levinson WE, Kurtzman CP, Kuo TM (2007) Characterization of Yarrowia lipolytica and related species for citric acid production from glycerol. Enzyme Microbiol Technol 41: 292-295.

9. HazerB, SteinbüchelA(2007) Increased diversification of polyhydroxyalkanoates by modification reactions for industrial and medical applications. Appl Microbio Biotechnol 74: 1-12. 
Citation: de Castro JS, Nguyen LD, Seppala J (2014) Bioconversion of Commercial and Waste Glycerol into Value-Added Polyhydroxyalkanoates by Bacterial Strains. J Microb Biochem Technol 6: 337-345. doi:10.4172/1948-5948.1000165

10. Canadas RF, Cavalheiro JM, Guerreiro JD, de Almeida MC, Pollet E, et al. (2014) Polyhydroxyalkanoates: Waste glycerol upgrade into electrospun fibrous scaffolds for stem cells culture. Int J Biol Macromol

11. Kadouri D, Jurkevitch E, Okon Y, Castro-Sowinski S (2005) Ecological and agricultural significance of bacterial polyhydroxyalkanoates. Crit Rev Microbiol 31: $55-67$.

12. Wang JG, Bakken LR (1998) Screening of Soil Bacteria for Poly-betaHydroxybutyric Acid Production and Its Role in the Survival of Starvation Microb Ecol 35: 94-101.

13. Ayub ND, Pettinari MJ, Ruiz JA, López NI (2004) A polyhydroxybutyrateproducing Pseudomonas sp. isolated from Antarctic environments with high stress resistance. Curr Microbiol 49: 170-174.

14. W Küng (1982) Poly-D(-)-3-Hydroxy-Buttersaeure-Akkumulation bei Alcaligenes Latus PhD Thesis Graz University of Technology.

15. Burdon KL (1946) Fatty Material in Bacteria and Fungi Revealed by Staining Dried, Fixed Slide Preparations. J Bacteriol 52: 665-678.

16. Spiekermann P, Rehm BH, Kalscheuer R, Baumeister D, Steinbüchel A (1999) A sensitive, viable-colony staining method using Nile red for direct screening of bacteria that accumulate polyhydroxyalkanoic acids and other lipid storage compounds. Arch Microbiol 171: 73-80.

17. Steinbüchel A, Wiese M (1992) A Pseudomonas strain accumulating polyesters of 3-hydroxybutyric acid and medium-chain-length 3-hydroxyalkanoic acids. Microbiol. Biotechnol 37: 691-697.

18. Männistö MK, Tiirola M, Häggblom MM (2007) Bacterial communities in Arctic fjelds of Finnish Lapland are stable but highly pH-dependent. FEMS Microbiol Ecol 59: 452-465.

19. Cavicchioli R, Siddiqui KS, Andrews D, Sowers KR (2002) Low-temperature extremophiles and their applications. Curr Opin Biotechnol 13: 253-261.

20. Quillaguamán J, Guzmán H, Van-Thuoc D, Hatti-Kaul R (2010) Synthesis and production of polyhydroxyalkanoates by halophiles: current potential and future prospects. Appl Microbiol Biotechnol 85: 1687-1696.

21. Van-Thuoc D, Quillaguamán J, Mamo G, Mattiasson B (2008) Utilization of agricultural residues for poly(3-hydroxybutyrate) production by Halomonas boliviensis LC1. J Appl Microbiol 104: 420-428.

22. Van-Thuoc D, Huu-Phong T, Thi-Binh N, Thi-Tho N, Minh-Lam D, et al. (2012) Polyester production by halophilic and halotolerant bacterial strains obtained from mangrove soil samples located in Northern Vietnam. Microbiologyopen 1: 395-406.

23. Kshirsagar P, Suttar R, Nilegaonkar S, Kulkarni S, Kanekar P (2012) Scale up production of polyhydroxyalkanoate (PHA) at different aeration, agitation and controlled dissolved oxygen levels in fermenter using Halomonas campisalis MCM B-1027. J Biochem Tech 4: 512-517.

24. Kachrimandou V, Kopsahelis N, Webb C, Koutinas AA (2014) Bioenergy research: Advances and Applications (Chapter 24) 419.

25. Quillaguamán J, Hashim S, Bento F, Mattiasson B, Hatti-Kaul R (2005) Poly(beta-hydroxybutyrate) production by a moderate halophile, Halomonas boliviensis LC1 using starch hydrolysate as substrate. J Appl Microbiol 99: 151157

26. Park SJ, Choi JI, Lee SY (2005) Engineering of Escherichia coli fatty acid metabolism for the production of polyhydroxyalkanoates. Enzyme Microbiol Technol 36: 579-588.

27. Tsuge $T$ (2002) Metabolic improvements and use of inexpensive carbon sources in microbial production of polyhydroxyalkanoates. J Biosci Bioeng 94: 579-584

28. Hatti-Kaul R, Törnvall U, Gustafsson L, Börjesson P (2007) Industrial biotechnology for the production of bio-based chemicals--a cradle-to-grave perspective. Trends Biotechnol 25: 119-124.

29. Xie QG, Taweepreda W, Musikavong C, Suksaroj C (2012) Removal of organic impurities in waste glycerol from biodiesel production process through the acidification and coagulation processes. Water Sci Technol 65: 1158-1163.

30. Goh YS, Tan IK (2012) Polyhydroxyalkanoate production by antarctic soil bacteria isolated from Casey Station and Signy Island. Microbiol Res 167: 211219.

31. Shrivastav A, Mishra SK, Shethia B, Pancha I, Jain D, et al. (2010)
Isolation of promising bacterial strains from soil and marine environment for polyhydroxyalkanoates (PHAs) production utilizing Jatropha biodiesel byproduct. Int J Biol Macromol 47: 283-287.

32. Moita R, Freches A, Lemos PC (2014) Crude glycerol as feedstock fo polyhydroxyalkanoates production by mixed microbial cultures. Water Res 58 9-20.

33. Cavalheiro JMBT, de Almeida MCMD, Grandfils C, Fonseca MMR (2009) Poly(3-hydroxybutyrate) production by Cupriavidus necator using waste glycerol. Proc Biochemist 44: 509-515.

34. Koller M, Hesse P, Bona R, Kutschera C, Atlić A, et al. (2007) Potential of various archae- and eubacterial strains as industrial polyhydroxyalkanoate producers from whey. Macromol Biosci 7: 218-226.

35. Yamane T, Fukunaga M, Lee YW (1996) Increased PHB productivity by highcell-density fed-batch culture of Alcaligenes latus, a growth-associated PHB producer. Biotechnol Bioeng 50: 197-202.

36. Lee SY, Choi J, Wong HH (1999) Recent advances in polyhydroxyalkanoate production by bacterial fermentation: mini-review. Int J Biol Macromol 25: 31 36 .

37. Huijbert GNN, van der Wal H, Weusthuis RA, Eggink G (1996) In: International Symposium on Bacterial Polyhydroxyalkanoates, Davos, Switzerland.

38. Suzuki T, Yamane S, Shimizu (1986) Mass production of poly- $\beta$-hydroxybutyric acid by fed-batch culture with controlled carbon/nitrogen feeding. Appl Env Microbiol 24: 370-374

39. Goff M, Ward PG, O'Connor KE (2007) Improvement of the conversion of polystyrene to polyhydroxyalkanoate through the manipulation of the microbial aspect of the process: a nitrogen feeding strategy for bacterial cells in a stirred tank reactor. J Biotechnol 132: 283-286.

40. Shah KR (2012) FTIR analysis of polyhydroxyalkanoates by a locally isolated novel Bacillus sp. AS 3-2 from soil of Kadi region, North Gujarat, India. J Biochem Tech 3: 380.

41. Yilmaz M, Soran $H$, Beyatli $Y$ (2005) Determination of poly- $\beta$-hydroxybutyrate (PHB) production by some Bacillus sp. World J Microbiol Biotech 21: 565-566.

42. Oliveira FC, Dias ML, Castilho LR, Freire DM (2007) Characterization of poly(3hydroxybutyrate) produced by Cupriavidus necator in solid-state fermentation. Bioresour Technol 98: 633-638.

43. Doi $Y$, Nakamura M, Kunioka K, Soga (1986) Nuclear magnetic resonance studies on poly( $\beta$-hydroxybutyrate) and a copolyester of $\beta$-hydroxybutyrate and $\beta$-hydroxyvalerate isolated from Alcaligenes eutrophus $\mathrm{H} 16$. Macromolecules 19: $2860-2864$.

44. Tanamool V, Imai T, Danvirutai $P$, Kaewkannetra P (2011) Biosynthesis of poly hydroxylalkanoate $(\mathrm{PHA})$ by Hydrogenophaga $\mathrm{sp}$. isolated from soil environments during batch fermentation. J Life Sciences 5: 1003-1012.

45. Du G, Chen J, Yu J, Lun S (2001) Continuous production of poly-3 hydroxybutyrate by Ralstonia eutropha in a two-stage culture system. J Biotechnol 88: 59-65.

46. Ojumu TV, Yu J, Solomon BO (2004) Production of polyhydroxyalkanoates, a bacterial biodegradable polymers. African J Biotechnol 3: 18-24.

47. Kunasundari B, Sudesh K (2011) Isolation and recovery of microbial polyhydroxyalkanoates. Polymer Lett 5: 620-634.

48. Martelli SM, Pietrini M, Fernandes EG, Chiellini E (2013) J Polym Environ 21 39. 